\title{
Impact of lubricant contamination with water on hydrodynamic thrust bearing performance
}

\author{
Elias Harika $^{1, a}$, Mathieu Helene ${ }^{1}$, Jean Bouyer ${ }^{2}$ and Michel Fillon ${ }^{2}$ \\ 1 EDF R\&D Département AMA/Groupe T63, 1 avenue du Général de Gaulle, Bureau IB008, 92141 Clamart Cedex, France \\ 2 Institut Pprime, Département Génie Mécanique et Systèmes Complexes CNRS, Université de Poitiers, ENSMA, UPR 3346, \\ SP2MI, Bd Marie et Pierre Curie, BP 30179, 86962 Futuroscope Chasseneuil Cedex, France
}

Received 2 December 2010, Accepted 9 June 2011

\begin{abstract}
Several studies have been carried out in order to describe the impact of water-contaminated lubricants on lubrication performance. One approach considers the water-contaminated oil as a homogeneous lubricant with physical characteristics varying with water concentration. The presented work is being achieved in order to experimentally validate this theory. First investigations showed that the variation of contaminated lubricant viscosity has the most significant effect on lubricating performance. Consequently, the lubricant viscosity is the only parameter taken into account in this study. Thus, based on the rheological measurements, water-in-oil emulsion viscosity has been modelled according to water concentration and temperature. Water concentration was considered relatively to total mass of oil: the mass concentration varied then from 0 to $7 \%$ and temperature from 10 to $80{ }^{\circ} \mathrm{C}$. Viscosity modelling was then used to perform the numerical simulations of a hydrodynamic thrust bearing supplied with water contaminated oil. Finally, the experimental validation will be done by measuring various bearing characteristics like the film/pad temperature, the film thickness and the friction torque on a tilting pad thrust bearing test rig.
\end{abstract}

Key words: Thrust bearing / tilting pads / water contamination / viscosity / emulsion

Résumé - Impact de la pollution des lubrifiants par de l'eau sur les performances d'une butée hydrodynamique. Plusieurs études ont été réalisées dans le but de décrire l'impact de la pollution des lubrifiants par de l'eau sur la lubrification. Une approche admissible pour répondre à cette problématique, considère l'huile polluée par de l'eau comme un lubrifiant homogène dont les caractéristiques physiques varient avec la concentration d'eau. Le travail présenté a pour but de valider cette théorie. Les premières investigations ont montré que la variation de la viscosité du lubrifiant pollué possède la plus grande influence sur les performances de lubrification. Nous ne considérerons donc dans cette étude que la variation de viscosité du lubrifiant avec la pollution. Ainsi, la viscosité de l'émulsion d'eau dans de l'huile a été modélisée en fonction de la concentration d'eau et de la température. La modélisation a été effectuée pour des conditions allant jusqu'à $7 \%$ massique en eau et jusqu'à $80^{\circ} \mathrm{C}$. Les résultats de cette modélisation ont été utilisés pour le calcul des caractéristiques statiques d'une butée hydrodynamique alimentée par une huile polluée par de l'eau. Enfin, les caractéristiques de lubrification, telles que le champ de température à l'interface film/patin, l'épaisseur du film d'huile ainsi que le couple de frottement, sont à mesurer sur un banc d'essais de butée hydrodynamique à patins oscillants.

Mots clés : Butée à patins oscillants / pollution par de l'eau / viscosité / émulsion

\section{Introduction}

Industrial lubrication systems are often subjected to different kinds of contamination which are very detrimental and sometimes fatal for some elements like bearings or pumps. Water in oil, likewise solid particles in oil, is one

${ }^{a}$ Corresponding author: elias.harika@edf.fr of the most known contamination issue in industrial applications. Indeed, this kind of contamination has a large impact on the flow characteristics within the film thickness, leading to unexpected behaviour or bearing damages. Consequences can be catastrophic.

Many studies were carried out in order to summarize water contamination sources or effects on lubrication. Water contamination can be due to seals defects or damage, 


\section{Nomenclature}

\begin{tabular}{|ll|}
\hline$T$ & Temperature (K) \\
$\varphi$ & Water volume fraction \\
$\lambda$ & Thermal conductivity $\left(\mathrm{W} . \mathrm{m}^{-1} \cdot \mathrm{K}^{-1}\right)$ \\
$\mu$ & Dynamic viscosity $(\mathrm{Pa} . \mathrm{s})$ \\
$k$ & Kinematic viscosity $(\mathrm{cSt})$ \\
$\rho$ & Density $\left(\mathrm{kg} . \mathrm{m}^{-3}\right)$ \\
$\omega$ & Rotational speed $(\mathrm{rpm})$ \\
$c_{p}$ & Specific heat $\left(\mathrm{kJ} . \mathrm{kg}^{-1} \cdot \mathrm{K}^{-1}\right)$ \\
\hline
\end{tabular}

heat exchangers cracks or simply, humidity exchange with air in tanks [1]. Water contamination effects are more complicated to describe and can be classified into two categories.

\subsection{Short-term effects}

The presence of water in lubrication circuits can decrease the bulk viscosity, and subsequently the lubricant film thickness, leading sometimes to metal to metal contact. Water can also favour cavitation phenomenon or decrease electrical resistance leading to electrostatic discharges, which can be very dangerous as well [2-4].

\subsection{Long-term effects}

Water being rich in oxygen, its presence can spark oil or metal oxidation phenomenon. Moreover, some lubricant additives can be inhibited by the presence of water, or even attacked chemically, resulting in acidic products which can be very dangerous for metals $[2,5,6]$.

The goal of the study is to evaluate the impact of water contamination on the lubricant viscosity and consequently on lubrication performances in order to define a critical water concentration threshold in lubrication systems. It assumes no secondary effects of water contamination like oxidation or cavitation.

The first part of the study will be devoted to a numerical study of an eight tilting pad thrust bearing. Lubrication characteristics like the film/pad interface temperature, the film thickness and the friction torque were calculated assuming that the bearing is supplied with a lubricant which has the same viscosity of water-in-oil emulsion. Other physical properties (specific heat, density, ...) were considered as constant with presence of water. Different water concentrations have been considered and results were compared to those got from identical calculations with neat oil.

While considering the approach of homogeneous water-in-oil emulsion, emulsion viscosity had to be defined according to water concentration. Nevertheless, water concentration is not the only parameter that affects the viscosity. Other parameters, such as temperature or droplet size, also contribute to define the viscosity [7].

One of the existing models of lubricating oils viscosity according to temperature variations is the

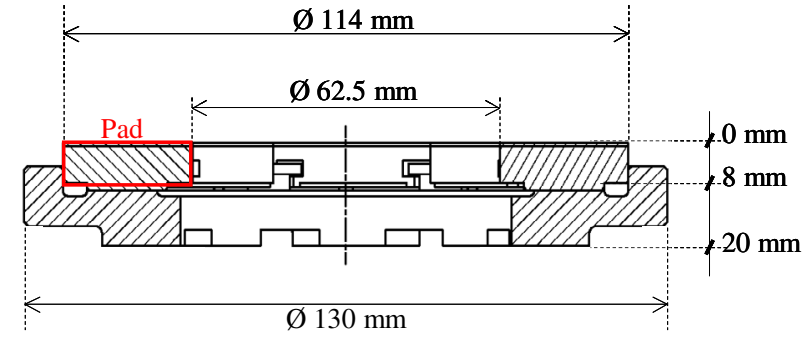

Fig. 1. Bearing dimensions.

MacCoull \& Walther law. This law has proved to be pertinent in most cases, and was considered in many studies. This law has been chosen in the present study, using an existing numerical code. It can be presented as follow [8]:

$$
\log (\log (k+0.7))=m \log T+n
$$

where " $m$ " and " $n$ " are constants.

Previous models of homogeneous water-in-oil emulsion viscosity, according to water concentration, for undefined droplet size distributions, are presented in literature $[9,10]$. However, because of the complexity of the situation, none of these models could satisfy the particular conditions of contaminated bearing feeding oils. Indeed, it has been decided to model the emulsion viscosity according to the water concentration, based on rheological measurements with the same droplet size conditions encountered in common thrust bearings.

The only noticeable information taken from literature is that the emulsion viscosity remarkably increases with water concentration, contrarily to what was expected. This led us to expect thicker lubricant film, while replacing neat oil with water-in-oil emulsion. This is the case only if homogeneous mixture assumption is correct.

The bearing geometry is described in the first paragraph, then some numerical results are presented in Section 2 , in order to highlight the effect of viscosity variation due to the presence of water in the lubricant. It will be showed that only viscosity has a significant impact on lubrication performances compared to other characteristics like specific heat or thermal conductivity. In the third section, the rheological modelling is described and, in the last part, some numerical results based on this viscosity modelling are presented in order to show the effect of lubricant contamination on lubrication.

\section{Bearing description}

For both numerical and experimental considerations, this study corresponds to the case of an eight tilting pad thrust bearing. For the experimental work, the chosen bearing is a flooded "Non-Equalizing" type thrust bearing provided by Kingsbury. Its main dimensions are shown in Figure 1. Each pad is included in a $40^{\circ}$ amplitude sector, which results in an active area of $5.614 \mathrm{~mm}^{2}$. Pads pivot offset is $57 \%$. 
Table 1. Density variation due to $7 \%$ of water.

\begin{tabular}{cccc}
\hline & $\rho$ at $20{ }^{\circ} \mathrm{C}$ & $\rho$ at $40{ }^{\circ} \mathrm{C}$ & $\rho$ at $60{ }^{\circ} \mathrm{C}$ \\
\hline Neat ISO VG 46 & $865 \mathrm{~kg} \cdot \mathrm{m}^{-3}$ & $855 \mathrm{~kg} \cdot \mathrm{m}^{-3}$ & $844.5 \mathrm{~kg} \cdot \mathrm{m}^{-3}$ \\
$7 \%$ water-in-oil & $873 \mathrm{~kg} \cdot \mathrm{m}^{-3}$ & $863.5 \mathrm{~kg} \cdot \mathrm{m}^{-3}$ & $853 \mathrm{~kg} \cdot \mathrm{m}^{-3}$ \\
Variation & $0.92 \%$ & $0.99 \%$ & $1 \%$ \\
\hline
\end{tabular}

The film/pad temperature, the film thickness and the friction torque can be measured on this bearing, for several lubricant types. First, an ISO VG 46 oil will be used, and later a water in ISO VG 46 emulsion will represent the contaminated oil.

\section{Secondary water-in-oil characteristics}

While considering water-in-oil emulsion as a homogeneous liquid, its most interesting characteristics from a lubrication standpoint are the following:

- the dynamic $(\mu)$ or kinematic $(k)$ viscosity (water-inoil emulsion has been found to have Newtonian behaviour [11]);

- the density $(\rho)$;

- the specific heat $\left(c_{p}\right)$;

- the thermal conductivity $(\lambda)$.

The effect of water on viscosity is detailed in Section 3, whereas this section is reserved to describe the variation of the other characteristics of water-in-oil emulsion according to the presence of water, and their effects on lubrication performances.

Being interested by the case of contaminated lubricants, water concentration was chosen to vary from 0 to $7 \%$ (masses proportions). In this paragraph, we will consider the effect of $7 \%$ water in an ISO VG 46 oil on the emulsion characteristics and we will compare the lubrication calculations to the case of neat oil lubricant:

\section{- Density $(\rho)$ :}

The oil density depends on temperature. It has been measured [12] for different temperatures, and then the density of $7 \%$ water-in-oil was calculated. Values are presented in Table 1.

- Specific heat $\left(c_{p}\right)$ :

By applying the equation:

$$
c_{p}(\text { emulsion })=c_{p}(\text { water }) \cdot X(\text { water })+c_{p}(\text { oil }) \cdot X(\text { oil })
$$

where $X$ (water) and $X$ (oil) are the mass fractions of respectively water and oil in the considered emulsion, and knowing that:

$$
\begin{aligned}
& c_{p}(\text { water })=4180 \mathrm{~kJ} \cdot \mathrm{kg}^{-1} \cdot \mathrm{K}^{-1} \\
& \quad \text { and } c_{p}(\text { oil })=2000 \mathrm{~kJ} \cdot \mathrm{kg}^{-1} \cdot \mathrm{K}^{-1}
\end{aligned}
$$

We obtain:

$$
c_{p}(7 \% \text { water-in-oil-emulsion })=2152.6 \mathrm{~kJ} \cdot \mathrm{kg}^{-1} \cdot \mathrm{K}^{-1}
$$

Equation (2) can be justified based on the definition of the specific heat " $c_{p}$ ". Indeed, the required heat to increase the temperature by $1 \mathrm{~K}$ of $1 \mathrm{~g}$ of water-in-oil emulsion is the sum of heat quantities required to increase by $1 \mathrm{~K}$ the temperature of both oil and water which constitute this emulsion.

- Thermal conductivity $(\lambda)$ :

The thermal conductivity of water-in-oil mixture depends on the thermal conductivities of both components and on the mixture structure. In the extreme case of separated phases, when the thermal flux lines are parallel to the interface between the oil and water, the mixture maximal thermal conductivity could be:

$$
\lambda_{\text {mixtue }}=\frac{\lambda_{\text {water }} \lambda_{\text {oil }}}{\varphi \lambda_{\text {oil }}+(1-\varphi) \lambda_{\text {water }}}
$$

where $\varphi$ is the water volume fraction. Equation (3) is based directly on the "Fourier Law" applied to the described case.

In the case of $7 \%$ of water-in-oil mixture this value corresponds to $0.1587 \mathrm{~W} . \mathrm{m}^{-1} \cdot \mathrm{K}^{-1}$, for:

$$
\lambda_{\text {water }}=0.6 \mathrm{~W} \cdot \mathrm{m}^{-1} \cdot \mathrm{K}^{-1} \text { and } \lambda_{\text {oil }}=0.13 \mathrm{~W} \cdot \mathrm{m}^{-1} \cdot \mathrm{K}^{-1}
$$

Some results from lubrication calculations, corresponding to a $7000 \mathrm{~N}$ load and a $10000 \mathrm{rpm}$ speed for the bearing presented in Section 1, are shown in Table 2. Values of film thickness and maximal film/pad interface temperature are compared considering the case of neat oil (first line) as a reference and varying the lubricant characteristic considered with a $7 \%$ water-in-oil mass concentration. In the case of neat oil (first line), the density was defined as $860 \mathrm{~kg} . \mathrm{m}^{-3}$.

As can be seen in Table 2, density has a slight influence on both film thickness and temperature. Effects of the specific heat are nearly twice those of the density, while the most important effect is that of the thermal conductivity on the film thickness. Nevertheless, the effects of the specific heat variation are adverse to those of the conductivity. Thus, one last calculation has been done with considering both specific heat and conductivity variations, which lead to $1.3 \%$ variation of film thickness and $0.8 \%$ variation of maximal temperature. These effects will be compared, in Section 4.2, to the effects of viscosity variation due to the presence of $7 \%$ of water in the oil.

N.B: The effects on lubrication seen in Table 2 can be explained as following:

- Density: when it increases, a same volume contains more lubricant; consequently, the same volume of lubricant can carry more heat. This leads to lower temperatures and higher local viscosities, which means thicker film. 
Table 2. Effects of secondary characteristics variation due to $7 \%$ water at $7000 \mathrm{~N} / 10000 \mathrm{rpm}$.

\begin{tabular}{ccc}
\hline & Film thickness $(\mu \mathrm{m})$ & Maximal temperature $\left({ }^{\circ} \mathrm{C}\right)$ \\
\hline Neat oil (reference case) & 45.11 & 95.1 \\
$\rho=870 \mathrm{~kg} \cdot \mathrm{m}^{-3}$ & $45.19(+0.2 \%)$ & $94.9(-0.2 \%)$ \\
$\rho=840 \mathrm{~kg} \cdot \mathrm{m}^{-3}$ & $44.98(-0.3 \%)$ & $95.6(+0.5 \%)$ \\
$c_{p}=2153 \mathrm{~J} \cdot \mathrm{kg}^{-1} \cdot \mathrm{K}^{-1}$ & $45.50(+0.9 \%)$ & $93.9(-1.3 \%)$ \\
$\lambda=0.16 \mathrm{~W} \cdot \mathrm{m}^{-1} \cdot \mathrm{K}^{-1}$ & $44.26(-1.9 \%)$ & $95.3(+0.2 \%)$ \\
\hline
\end{tabular}

- Specific heat: when it increases, the lubricant coolant property is enhanced, which means lower temperature, higher local viscosity and thicker film.

- Thermal conductivity: it is also a characteristic of a good coolant; nevertheless, for same conditions of heat fluxes, the fluid temperature is higher which means lower local viscosity and thinner film.

\section{Water-in-oil emulsion viscosity}

This paragraph deals with rheological measurements and viscosity modelling of water contaminated lubricants. The aim of this work is to define a law of water-in-oil viscosity variation with water concentration, for a given temperature. Nevertheless, it is shown that temperature variations change the effect of water concentration on viscosity. Consequently, we tried to model the viscosity according to both temperature and concentration. This task was not straightforward and not practical to achieve lubrication calculations [12]. Thus, the MacCoull \& Walther law was directly used for each water concentration, with different specific coefficients.

\subsection{Measurement points}

Water-in-oil emulsion viscosity has been measured for ten water concentrations: $0 \%, 0.2 \%, 0.3 \%, 0.5 \%, 0.7 \%$, $1 \%, 2 \%, 3 \%, 5 \%$, and $7 \%$ (mass fractions), considering ISO VG 46 oil without any oil additive.

For each water concentration, measurements were achieved for five different temperatures: $10{ }^{\circ} \mathrm{C}, 20{ }^{\circ} \mathrm{C}$, $40{ }^{\circ} \mathrm{C}, 60^{\circ} \mathrm{C}$ and $80{ }^{\circ} \mathrm{C}$.

\subsection{Materials preparation}

Emulsions were prepared by a HMG homogenizer (Pharmag), presented in Figure 2, wherein the liquid is pushed by a piston against the tip of a nozzle, and submits to cracking.

First of all, about 11 of oil is poured in the mixer tank after being weighed on a precision balance with an accuracy of $0.1 \mathrm{~g}$. According to the required mass percentage, the corresponding mass of water is then added into the same tank. The mixer is started and kept running for $20 \mathrm{~min}$ at a rotational speed of $150 \mathrm{rpm}$.

Several observations made by means of an optical microscope showed that for these conditions of mixing,

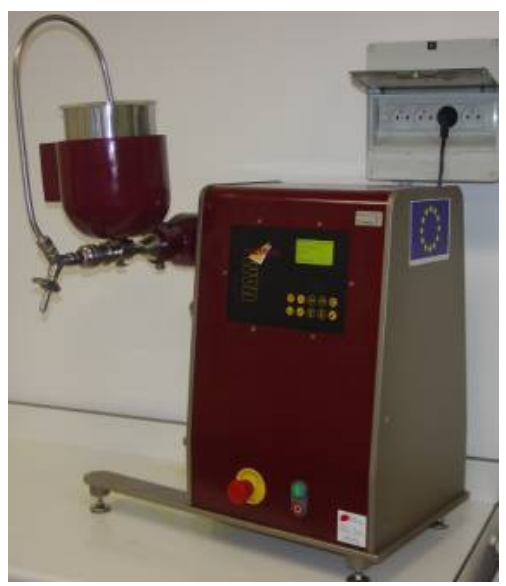

Fig. 2. Homogenizer.

water-in-oil emulsion reached the same maximum water droplet size of about $30 \mu \mathrm{m}$.

After preparing the $1 \mathrm{l}$ emulsion, a sampling is carried out for viscosity measurement at the temperature of $10{ }^{\circ} \mathrm{C}$. After this first measurement, and before each sampling corresponding to another temperature, the mixer is kept running for another $20 \mathrm{~min}$, in order to avoid the sedimentation phenomenon which is supposed to disrupt the emulsion structure. When measurements are completed for all temperatures at the same water concentration, the mixer tank is cleaned out and refilled again in the same manner with the next components fraction.

\subsection{Measurements procedure}

Viscosity measurements were carried out with a Gemini controlled stress rheometer (Malvern) (Fig. 3). Coaxial cylinders geometry was chosen, in which the rotor is a solid cylinder of $33.7 \mathrm{~mm}$ diameter, and $37.9 \mathrm{~mm}$ height. The stator is an empty cylinder of $36.7 \mathrm{~mm}$ diameter.

The cylinder which contains the sample is equipped with a thermal control device, in order to make measurements at different temperatures as desired.

To ensure a good measurement procedure, the sample is poured into the cylinder, then the temperature is set, and the viscosity is measured after the thermal stability is reached inside the cylinder. The time needed to reach the thermal stability depends on the temperature difference between the initial sample temperature and the set point. For instance, in order to make measurements at $20{ }^{\circ} \mathrm{C}$ for a $23{ }^{\circ} \mathrm{C}$ sample temperature, $10 \mathrm{~min}$ are required to ensure a good thermal stability. 


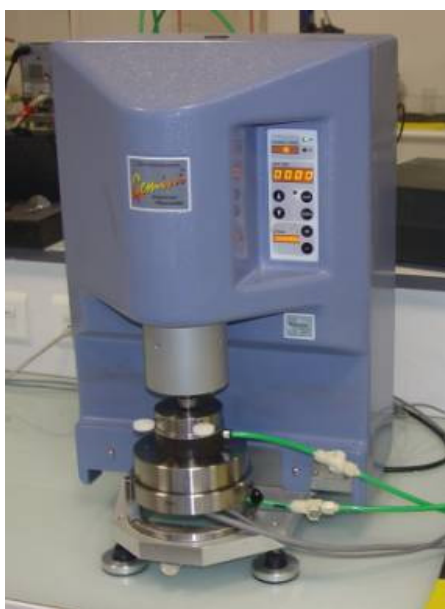

Fig. 3. Rheometer.

\subsection{Difficulties}

Measurements being achieved without any additives, a sedimentation phenomenon made it difficult to measure the real viscosity of emulsion for some extreme conditions. Indeed, the emulsion structure disruption due to sedimentation is, in some conditions of temperature and water concentration, quickest than the thermal stability. So we had to fix this issue and find simple solutions to achieve the work, like heating the sample during the mixing phase without overtaking components evaporating limits. In addition, a correction had to be done for some extreme condition measurements, based on specific supplementary tests [12].

\subsection{Results and modelling}

For all temperatures, results show that viscosity is increasing with water concentration. Thus, for $0.2 \%$ of water concentration, emulsion viscosity is higher than the neat oil viscosity and keeps increasing for the other concentrations. Meanwhile, temperature effect is well shown when the relative viscosity is plotted, for each temperature, according to water concentration (Fig. 4). Relative viscosity is the ratio of emulsion viscosity to the neat oil viscosity at same temperature. As it can be seen in Figure 4, for a given water concentration, the relative viscosity decreases with temperature. This means that the effect of the same quantity of water is not the same, but it depends on temperature. Thus, for a higher temperature, the viscosity increase, due to the same quantity of water, is lower.

The viscosity variation as a function of temperature is shown in Figure 5, for the neat oil and for $7 \%$ water concentrated emulsion. Values of viscosity corresponding to the other concentrations are comprised between these two curves, sorted by ascending order, according to water concentration. As it can be seen on this graph, the curve shape corresponding to the neat oil is conserved when the viscosity is varying with the concentration. This shape

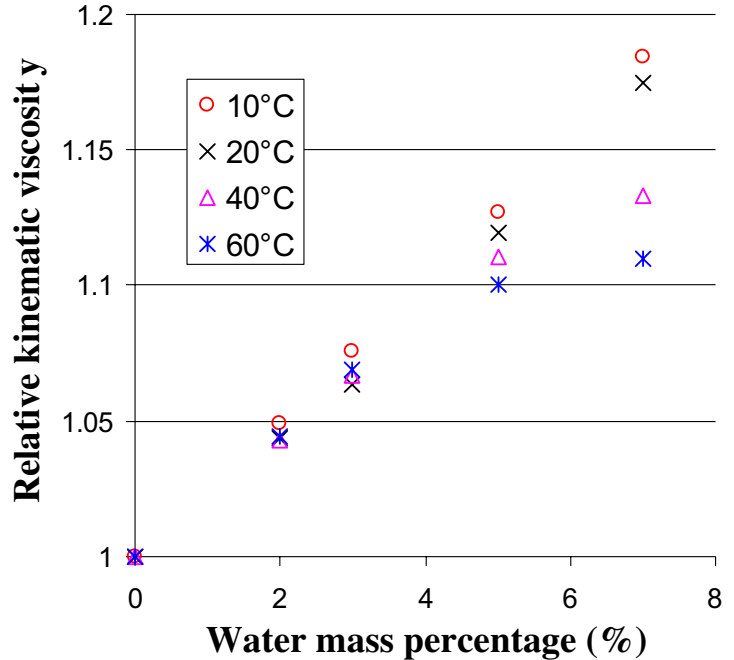

Fig. 4. Relative viscosity according to water concentration.

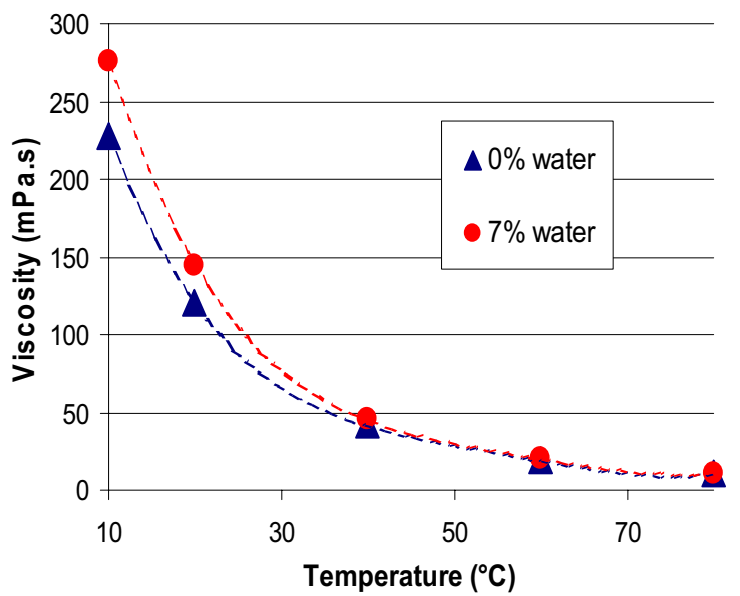

Fig. 5. Dynamic viscosity according to temperature.

fits with the law of MacCoull \& Walther. Figure 6 shows two examples of fitting of this model to the measured viscosity values for $0.3 \%$ water (Fig. 6a) and $5 \%$ water (Fig. 6b). These fittings were found to be pertinent for all the measurements.

Thus, for the theoretical part of this study, the contaminated lubricant will be considered as a homogeneous fluid which has the same properties of the neat lubricant. Its viscosity will be considered to respect the law of MacCoull \& Walther but with different coefficients than those of neat oil.

\section{Numerical calculation}

\subsection{Procedure}

Based on lubrication fundamental equations and on the MacCoull \& Walther law for lubricant viscosity, the numerical THD (Thermo-Hydro-Dynamic) modelling permits the calculation of several lubrication static performances. Among these characteristics the film/pad temperature, the film thickness and the friction torque are 


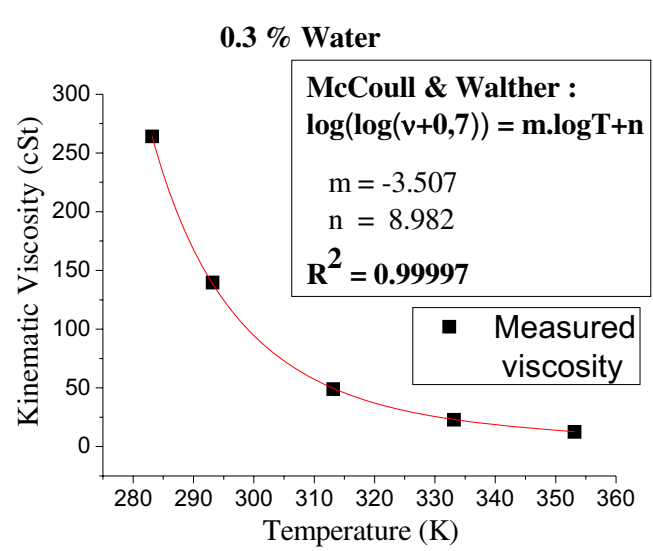

(a)

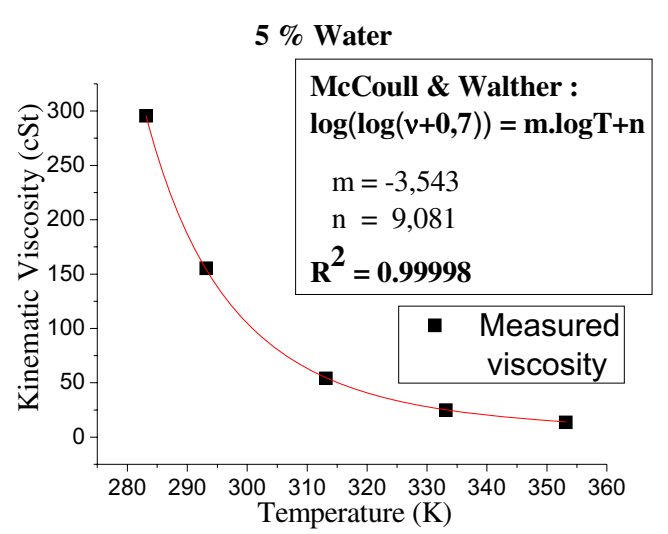

(b)

Fig. 6. Fittings of the Mac Coull \& Walther law to measurements.

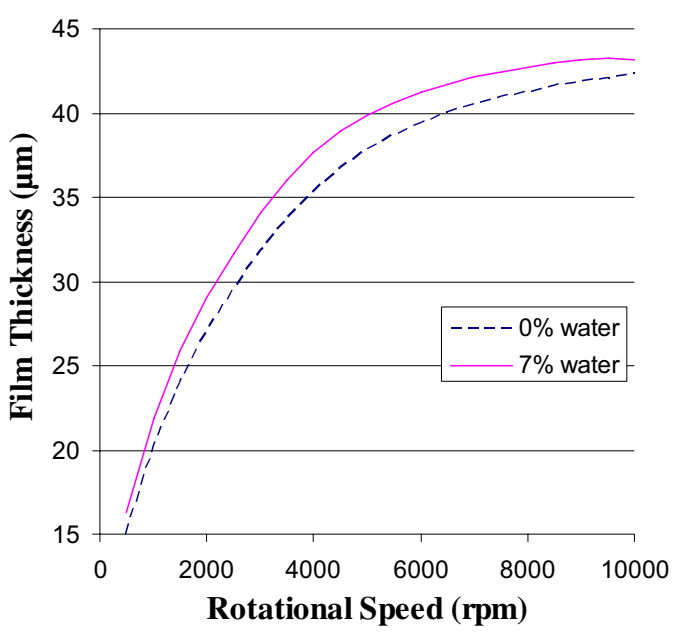

(a)

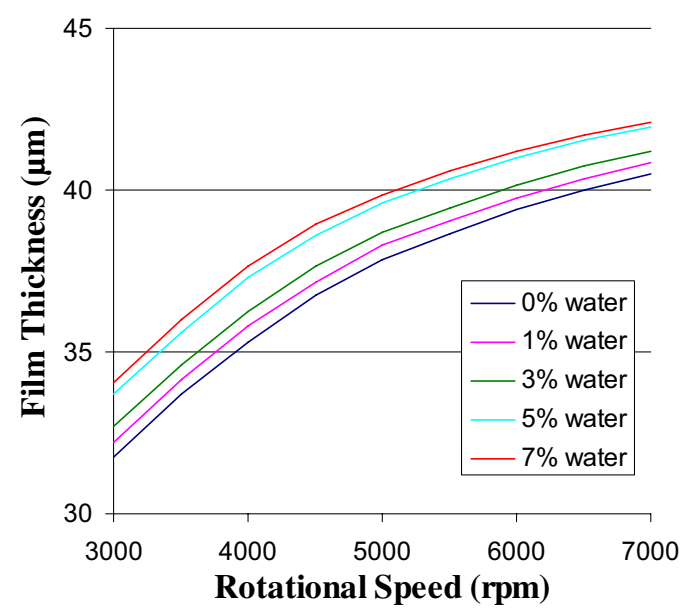

(b)

Fig. 7. Variations of the effective film thickness (at the pivot) due to water concentration at $7000 \mathrm{~N}$.

the most representative and practical to be measured for a later comparison. Load has been chosen to vary from 1000 to $10000 \mathrm{~N}$, with a $1000 \mathrm{~N}$ step, and speed from 500 to $10000 \mathrm{rpm}$, with a $500 \mathrm{rpm}$ step. The lubricant characteristics in the case of the neat oil correspond to an ISO VG 46 oil. After achieving all calculation for the neat oil, only the viscosity law has been modified, for a next calculation, by the one corresponding to the waterin-oil emulsion at a different concentration each time. The values were defined based on rheological measurements presented above.

\subsection{Results}

For the same case of calculation point presented in Section 2, Table 3 shows the values of film thickness and maximal temperature corresponding to the variation of just the viscosity due to $7 \%$ of water, which must be compared to values in Table 2 .
Table 3. Effects of viscosity variation due to $7 \%$ water at $7000 \mathrm{~N} / 10000 \mathrm{rpm}$.

\begin{tabular}{lcc}
\hline & $\begin{array}{c}\text { Film thickness } \\
(\mu \mathrm{m})\end{array}$ & $\begin{array}{c}\text { Maximal temperature } \\
\left({ }^{\circ} \mathrm{C}\right)\end{array}$ \\
\hline $\begin{array}{l}\text { Neat oil } \\
\text { (reference case) }\end{array}$ & 45.11 & 95.1 \\
$\begin{array}{l}\text { Viscosity of } \\
7 \% \text { water }\end{array}$ & $46.91(+4.0 \%)$ & $97.2(+2.2 \%)$ \\
\hline
\end{tabular}

The viscosity variation of the lubricant due to the presence of water in the oil proved to have the most important effect on the lubrication.

More results are presented in Figure 7, where the film thickness variation, at the pivot level (called effective thickness), is plotted as a function of the rotational speed " $\omega$ " for a $7000 \mathrm{~N}$ load and different water concentrations. This figure shows that the most important effect of water-in-oil is to increase the film thickness. This effect is directly due to the increase of viscosity resulting from water presence. 


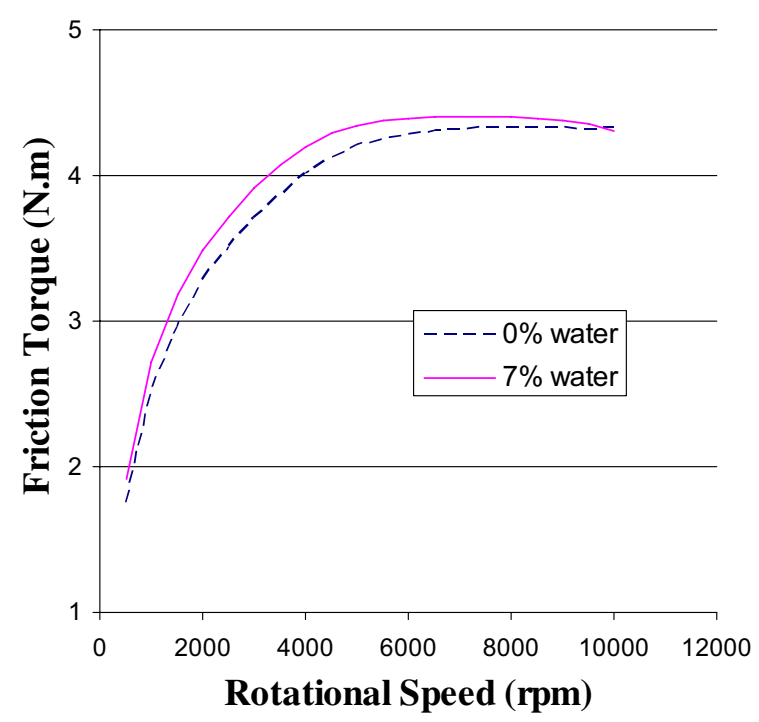

Fig. 8. Variation of friction torque due to $7 \%$ of water at $7000 \mathrm{~N}$.

On the other hand, the effect of water-in-oil on temperature and friction is detrimental, as the friction torque and maximal temperature increase slightly with the water contamination (2 to $4 \%$ variations for $7 \%$ of water) (Figs. 8 and 9). Nevertheless, these variations could be ignored, especially because the acceptable tolerance of these parameters is relatively bigger comparing to that of film thickness.

The effect of water concentration on lubrication characteristics has been found to depend on the operating conditions, especially on speed (Figs. 7a, 8 and 9). Indeed, the increase of lubricant viscosity can lead to higher film thickness, which is predicted directly by Reynolds equation in the case of hydrodynamic lubrication. Higher viscosity increases also the friction and consequently, the temperature. Meanwhile, the temperature increase has a decreasing effect on viscosity, subsequently on friction and film thickness. So viscosity increase has two adverse effects on lubrication characteristics, and in a real case, an equilibrium point is reached for every operating condition. The variation of this equilibrium point due to viscosity change is not the same for each condition. Anyway, it has been found to move in the direction of thicker film in all cases.

\section{Conclusions}

The viscosity of water-in-oil emulsion has been measured and modelled for widespread variations of temperature and water concentration, without any additives. The results of our numerical simulations have showed that the viscosity has the most significant influence on bearing performances when compared to the influence of the other physical characteristics of the emulsion. The pollution of the oil with water leads to an improving effect of lubrication conditions rather than detrimental one. This analysis is based on a homogeneous mixture assumption. In order

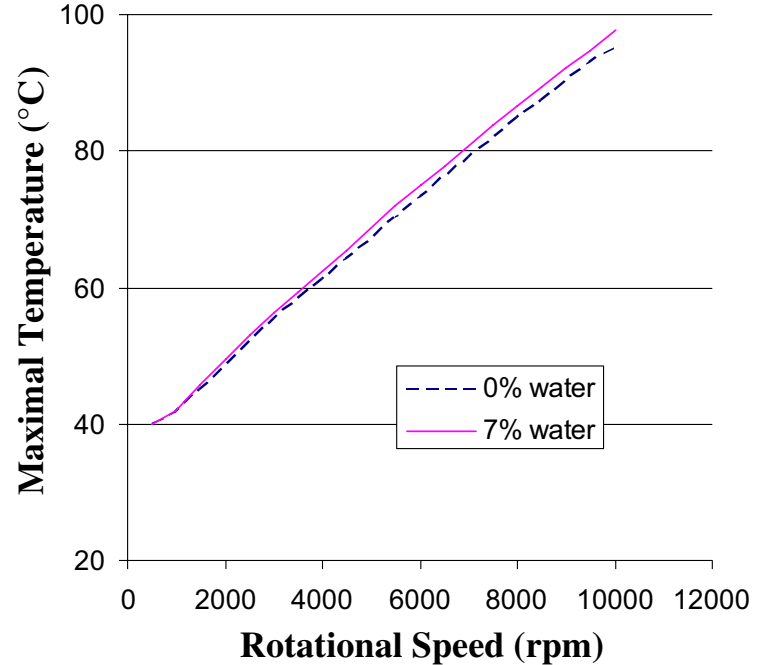

Fig. 9. Variation of Maximal Temperature due to $7 \%$ of water at $7000 \mathrm{~N}$.

to validate this hypothesis, an additional experimental work has to be performed in the next future.

\section{References}

[1] H. Bloch, Criteria for water removal from mechanical drive steam turbine lube oils, J. Amer. Soc. Lubrication Eng. 36 (1980) 699-707

[2] A.C. Eachus, Water, water everywhere nor any drop to drink, Trib. Lubrication Tech. (2005) 33-39

[3] H. Prashad, A study of electrical pitting of journal bearings with water-contaminated lubricant, Tribotest J. 7 (2000) 115-124

[4] A. Dadouche, W. Dmochowski, On the effects of oil contamination on the performance of plain journal bearings, 5th EDF \& LMS Poitiers Workshop, 2006

[5] R.W. Wilson, Corrosion of tin base babbitt bearings in marine steam turbines, Trans. Inst. Marine Eng. 73 (1961) 11

[6] J.W. Mac Donald, Marine turbine oil system maintenance, J. Amer. Soc. Lubrication Eng. 21 (1965) 429-432

[7] R.A. Lionberger, Viscosity of bimodal and polydesperse colloidal suspensions, Phys. Rev. E 65 (2002) 061408

[8] N. Mac Coull, C. Walther, Viscosity-Temperature chart, Lubrication, 1921

[9] G.I. Taylor, The viscosity of a fluid containing small drops of another fluid, P. Roy. Soc. Lond. A Mat. 138 (1932) $41-48$

[10] R. Pal, Evaluation of theoretical viscosity models for concentrated emulsions at low capillary numbers, Chem. Eng. J. 81 (2001) 15-21

[11] R. Pal, E. Rhodes, A novel viscosity correlation for nonNewtonian concentrated emulsions, J. Colloid Interf. Sci. 107 (1985) 301-307

[12] E. Harika, S. Jarny, P. Monnet, J. Bouyer, M. Fillon, Effect of water pollution on rheological properties of lubricating oil, Appl. Rheol. 21 (2011) 1-9 